\title{
Comunicação
}

[Communication]

\section{Ocorrência de anticorpos anti-Toxoplasma gondii em emas (Rhea americana) do Centro de Multiplicação de Animais Silvestres de Mossoró, Rio Grande do Norte}

[Occurrence of anti-Toxoplasma gondii antibodies in greater rheas (Rhea americana) at the Reproduction Centre for Wild Animals in Mossoró, Rio Grande do Norte, Brazil]

\author{
H.S. Soares ${ }^{1}$, N.D. Alves ${ }^{1 *}$, R.H.M.A. Pereira ${ }^{1}$, S.M. Matos ${ }^{1}$, H.F.J. Pena ${ }^{2}$, S.M. Gennari ${ }^{2}$, \\ F.M.C. Feijó ${ }^{1}$, S.S.A. Amóra ${ }^{1}$, G.C.X. Peixoto ${ }^{1}$ \\ ${ }^{1}$ Curso de Medicina Veterinária - UFERSA - Mossoró, RN \\ ${ }^{2}$ Faculdade de Medicina Veterinária e Zootecnia - USP - São Paulo, SP
}

A toxoplasmose, zoonose causada pelo protozoário Toxoplasma gondii, apresenta distribuição mundial e taxa de prevalência variável nas diversas partes do globo (Tenter et al., 2000),

Dentre os testes sorológicos disponíveis, a técnica da aglutinação modificada (MAT) constitui um método de diagnóstico de $T$. gondii bastante utilizado em diferentes espécies animais, pois apresenta boa sensibilidade e especificidade, não exige equipamentos especiais nem conjugados espécie-específicos, o que faz dela uma técnica muito útil, em especial em animais silvestres (Dubey, 2002).

A ema (Rhea americana) é uma ave genuinamente sul-americana, de grande porte, não voadora, com ampla distribuição geográfica e boa adaptação em clima seco. É onívora, com dieta composta de gramíneas, leguminosas e pequenos animais como cobras, ratos, lagartos e insetos (Aguiar e Mauro, 2004).

Em relação ao T. gondii, a infecção pelo agente já foi demonstrada em várias espécies de aves (Dubey, 2002) tanto de cativeiro quanto de vida livre, entretanto existem poucos estudos (Marobin et al., 2004; Leite et al., 2007) no Brasil apesar da grande diversidade da fauna silvestre aviária.

Recebido em 19 de novembro de 2009

Aceito em 12 de março de 2010

*Autor para correspondência (corresponding author)

Email: nilzadutra@yahoo.com.br
O presente estudo teve por objetivo a pesquisa de anticorpos anti-T. gondii em emas do Centro de Multiplicação de Animais Silvestres (CEMAS) alocado na Universidade Federal Rural do Semiárido, em Mossoró, Rio Grande do Norte, por MAT. O CEMAS é registrado junto ao IBAMA como criatório científico ( $\left.\mathrm{N}^{\mathrm{o}} 12.492 / 0004\right)$.

Amostras de sangue de 69 emas foram obtidas utilizando-se tubos a vácuo (Vacutainer ${ }^{\circledR}$ ) por meio de venopunção braquial. As amostras foram centrifugadas, e os soros identificados e armazenados a $-20^{\circ} \mathrm{C}$ até a análise. Das aves amostradas, $45(65,2 \%)$ eram fêmeas e 24 machos $(34,8 \%)$, com idade variando de três e oito anos. O MAT foi realizado no Laboratório de Doenças Parasitárias do Departamento de Medicina Veterinária Preventiva e Saúde Animal - FMVZ-USP, de acordo com o método descrito por Dubey e Desmonts (1987), utilizando-se ponto de corte 1:25, e as amostras positivas foram diluídas e tituladas.

Foram encontradas três $(4,3 \%)$ amostras positivas $\left(\chi^{2}=1,57, \mathrm{P}=0,21\right)$, todas provenientes de fêmeas com cinco anos de idade, e títulos de 1:50, 1:100 e 1:200. Estes resultados são semelhantes aos de Mineo et al. (2009), que afirmaram que os títulos de $\operatorname{IgG}$ para $T$. gondii em aves são elevados no início da infecção e tornam-se baixos ou não detectáveis após a 
infecção, diferentemente do que ocorre em mamíferos. Vitaliano (2007) verificou que a soroconversão de carcarás (Caracara plancus) experimentalmente infectadas ocorreu a partir do sétimo dia pós-infecção, sendo que em seguida houve uma tendência de diminuição de anticorpos circulantes, chegando a níveis indetectáveis em uma das aves no $68^{\circ} \mathrm{DPI}$.

Marobin et al. (2004), ao estudarem 74 emas de criatórios comerciais no Rio Grande do Sul, encontraram 8,1\% de ocorrência de $T$. gondii, pela reação de hemaglutinação. No presente estudo, a ocorrência foi mais baixa, entretanto, devido ao uso de métodos de diagnóstico diversos, comparações de valores de ocorrência devem ser feitas com prudência.

No Brasil, estudos com aves de cativeiro e ocorrência de $T$. gondii são poucos. Leite et al. (2007), ao estudarem pássaros da família Cracidae provenientes do criadouro no Estado de Pernambuco, avaliaram 252 aves dos gêneros Aburria, Crax, Mitu, Notocrax, Ortalis, Pauxi, Penelope e Pipile pelo teste de hemaglutinação indireta e verificaram a ocorrência de 84,9\%. Contente (2006), ao utilizar avestruzes (Struthio camelus) de criatórios comerciais de São Paulo e o MAT ( $\geq 16)$ como método de diagnóstico, encontrou $14,4 \%$ de positividade. Em outros estudos realizados também com avestruzes no Canadá (Dubey et al., 2000) e no Zimbábue (Hove e Mukaratirwa, 2005), a ocorrência foi de $2,9 \%$ e $48 \%$, respectivamente, e também nesses estudos o diagnóstico foi feito pelo MAT.

Estudos de infecção por T. gondii em aves têm mostrado um comportamento bastante distinto entre diferentes espécies, com algumas altamente susceptíveis à infecção e quadro clínico severo e outras espécies muito resistentes (Dubey, 2002). Em relação às emas, não há estudos de infecção experimental que indiquem estarem estas entre as espécies resistentes ou susceptíveis ao parasito. Desse modo, merecem maior atenção, sendo importante o diagnóstico e o controle do $T$. gondii nessa espécie.

Palavras-chave: Toxoplasma gondii, ema, Rhea americana, anticorpos

\begin{abstract}
Anti-Toxoplasma gondii antibodies were evaluated in greater rheas (Rhea americana) from the Reproduction Centre for Wild Animals located at the Universidade Federal Rural do Semiárido in the city of Mossoró, Rio Grande do Norte, by the modified agglutination test (MAT $\geq 25)$. It was verified that, from the 69 examined birds, 4.3\% (three rheas) tested positive. The research about ratites toxoplasmoses are scarce, this way, the results showed the importance of the T. gondii diagnosis in wild birds.
\end{abstract}

Keywords: Toxoplasma gondii, rhea, Rhea americana, antibodies

\section{AGRADECIMENTO}

Ao Dr. J.P. Dubey, United States Department of Agriculture, Agricultural Research Service, Animal and Natural Resources Institute, Animal Parasitic Diseases Beltsville, MD, USA, pelo envio do kit utilizado para o diagnóstico.

\section{REFERÊNCIAS BIBLIOGRÁFICAS}

AGUIAR, L.M.S.; MAURO, R.A. Ema - Rhea americana. Fauna e Flora do Cerrado, Campo Grande, Junho 2004. Disponível em: < http://www.cnpgc.embrapa.br/series/ema/Ema.ht m >. Acessado em: 19 fev. 2008.
CONTENTE, A.P.A. Prevalência de anticorpos anti-Toxoplasma gondii em avestruzes (Struthio camelus) de criatórios comerciais no Estado de São Paulo. 2006. 56f. Dissertação (Mestrado) Faculdade de Medicina Veterinária e Zootecnia, Universidade Estadual Paulista, Botucatu, SP.

DUBEY, J.P. A Review of toxoplasmosis in wild birds. Vet. Parasitol., v.106, p.121-153, 2002.

DUBEY, J.P.; DESMONTS, G. Serological responses of equids fed Toxoplasma gondii oocysts. Equine Vet. J., v.19, p.337-339, 1987.

DUBEY, J.P.; SCANDRETT, W.B.; KWORK, O.C.H. et al. Prevalence of Antibodies to Toxoplasma gondii in Ostriches (Struthio camelus). J. Parasitol., v.86, p.623-624, 2000. 
HOVE, T.; MUKARATIRWA, S Seroprevalence of Toxoplasma gondii in farm reared ostriches and wild game species from Zimbabwe. Acta Trop., v.94, p.49-53, 2005.

LEITE, A.S.; ALVES L.C.; FAUSTINO M.A.G. Serological survey of toxoplasmosis in birds from Cracidae family in a wild bird center facility at Pernambuco State, Northeast of Brazil. Med. Vet., v.1, p.55-57, 2007.

MAROBIN, L.; FLÔRES, M.L.; RIZZATI, B.B. et al. Prevalência de anticorpos para Toxoplasma gondii em emas (Rhea americana) em diferentes criatórios do Estado do Rio Grande do Sul. Braz. J. Vet. Res. Anim. Sci., v.41, p.5-9, 2004.
MINEO, T.W.P.; CARRASCO; A.O.T., MARCIANO, J.A. et al. Pigeons (Columbia Lívia) are a suitable experimental model for Neospora caninum infection in birds. Vet. Parasitol., v.159, p.149-153, 2009.

TENTER, A.M.; HECKEROTH, A.R.; WEISS, L.M. Toxoplasma gondii: from animals to humans. Inter. J. Parasitol., v.30, p.1217-1258, 2000 .

VITALIANO, S.N. Infecção Experimental em carcarás (Caracara plancus, Miller, J.F., 1777) com Toxoplasma gondii (amostra ME49). 2007. 65f. Dissertação (Mestrado) - Faculdade de Medicina Veterinária e Zootecnia, Universidade Estadual Paulista, Jaboticabal, SP. 